Revista Brasileira de Agricultura Irrigada v.14, no .4, p. 4200 - 4210, 2020

ISSN 1982-7679 (On-line)

Fortaleza, CE, INOVAGRI - http://www.inovagri.org.br

DOI: $10.7127 /$ rbai.v14n401196

Protocolo 1196.20 - 29/10/2020 Aprovado em 26/01/2021

\title{
PRODUTIVIDADE DA CULTURA DA SOJA IRRIGADA COM DÉFICIT HÍDRICO REGULADO NO CERRADO PIAUIENSE
}

\author{
Jaildo Ribeiro Barbosa ${ }^{1}$, João Valdenor Pereira Filho ${ }^{2}$, Valdir Moura de Oliveira ${ }^{1}$, Geocleber Gomes \\ de Sousa ${ }^{3}$, Geovana Ferreira Goes ${ }^{4}$, Kelly Nascimento Leite ${ }^{5}$
}

\begin{abstract}
RESUMO
As culturas agrícolas apresentam estádios fenológicos de menor suscetibilidade ao déficit hídrico do solo, nos quais a estratégia de manejo da irrigação deficitária pode ser empregada, no intuito de maximizar a produção por unidade de água aplicada. Neste contexto, objetivou-se avaliar as características produtivas de duas cultivares de soja (NS8397 e J003) sob irrigação com déficit controlado nas diferentes fases de desenvolvimento. $\mathrm{O}$ delineamento experimental adotado foi o de blocos casualizados em esquema de parcelas subdivididas, com dezesseis tratamentos e três repetições. Os tratamentos considerados parcelas, consistiram nas aplicações da imposição ou não do déficit hídrico (50 e 100\% da ETo) em diferentes estádios de desenvolvimento e nas subparcelas as cultivares. A irrigação com déficit controlado ocasionou alterações em todas as componentes de produção, exceto no número de ramificações. As componentes produtivas da cultura da soja (altura de inserção da primeira vagem, número de vagens por planta, número de grãos por planta e o potencial produtivo total) obtiveram melhores respostas, principalmente, quando irrigadas com uma lâmina de irrigação referente a $100 \%$ da ETo durante o estádio fenológicos I. O déficit hídrico controlado (50\% da ETo) aplicado, principalmente, nas fases de floração e enchimento de grãos na cultura soja, ocasionou diminuições drásticas nas componentes produtivas (número de vagens por planta, número de grãos por planta e potencial produtivo total). A cultivar NS 8397 demonstrou ser mais adaptada e tolerante as condições de déficit hídrico impostas, sendo, portanto, mais recomendada para o cultivo na região do cerrado sul piauiense.
\end{abstract}

Palavras-Chave: Glycine max (L.) Merrill, manejo da irrigação, oleaginosa

\footnotetext{
1 Graduando em Agronomia da Universidade Estadual do Piauí (UESPI), CEP: 64860-000, Uruçuí-Piauí. Email: jaildoagro.uespi@gmail.com; tiovaldir64@gmail.com

2 Professor da Universidade Estadual do Piauí (UESPI), Campus Cerrado do Alto Parnaíba, Uruçuí - PI. Email: joaovaldenor@urc.uespi.br

${ }^{3}$ Professor da Universidade da Integração Internacional da Lusofonia Afro-Brasielira, Instituto de Desenvolvimento Rural, Redenção-CE. E-mail: sousagg@unilab.edu.br

${ }^{4}$ Graduanda em Agronomia da Universidade da Integração Internacional da Lusofonia Afro-Brasielira, Instituto de Desenvolvimento Rural, Redenção-CE. E-mail: ggoes64@gmil.com

${ }^{5}$ Professora da Universidade Federal do Acre, Cruzeiro do Sul - AC. E-mail: knleite.ufac@gmail.com
} 


\title{
PRODUCTIVE COMPONENTS IN IRRIGATED SOYBEAN CROP WITH REGULATED WATER DEFICIT IN THE EDAPHOCLIMATIC CONDITIONS OF THE CERRADO PIAUIENSE
}

\begin{abstract}
Agricultural crops have phenological stages that are less susceptible to soil water deficit, in which the deficit irrigation management strategy can be used, in order to maximize production per unit of water applied. In this context, the objective was to evaluate the productive characteristics of two soybean cultivars (NS 8397 and J003) under irrigation with controlled deficit in the different stages of development. The experimental design adopted was randomized blocks in a split plot scheme, with sixteen treatments and three replications. The treatments considered plots, consisted of the applications of the imposition or not of the water deficit (50 and 100\% of ETo) in different stages of development and in the subplots the cultivars. Controlled deficit irrigation caused changes in all production components, except for the number of branches. The productive components of the soybean crop (height of insertion of the first pod, number of pods per plant, number of grains per plant and the total productive potential) obtained better responses, mainly when irrigated with an irrigation blade referring to $100 \%$ of the ETo during the phenological stage I. The controlled water deficit (50\% of ETo) applied, mainly, in the flowering and grain filling phases in the soybean crop, caused drastic decreases in the productive components (number of pods per plant, number of grains per plant and total productive potential). The cultivar NS 8397 proved to be more adapted and tolerant to the water deficit conditions imposed, being, therefore, more recommended for cultivation in the Cerrado region of southern Piauí.
\end{abstract}

Keywords: Glycine $\max ($ L.) Merrill, irrigation management, oilseed

\section{INTRODUÇÃO}

A cultura da soja é o principal produto da agricultura piauiense, com cerca de $52 \%$ da produção, seguido do milho com cerca de $42 \%$. A produção total de grãos esperada para o Piauí, no primeiro prognóstico de 2020, com dados divulgados pelo Escritório Técnico de Estudos Econômicos do Nordeste (ETENE), é um recorde na série histórica, com valores da ordem de 4,89 milhões de toneladas. Isso representa um aumento de $10,84 \%$ em relação à safra obtida em 2019, que foi de 4,42 milhões de toneladas (BANCO DO NORDESTE, 2020).

De acordo com o censo agropecuário 2017, o município de Uruçuí produziu 322.831 toneladas de grãos de soja, com uma área total colhida de 113.830 hectares, perdendo apenas para o município de Baixa Grande do Ribeiro, que produziu 548.097 toneladas de grãos em uma área colhida de 177.332 hectares (IBGE, 2019). Segundo dados da Fundação CEPRO (2019), Entre os municípios com maiores PIBs per capita em 2017, oito tinham como principal atividade a Agropecuária, sendo todos situados na região do cerrado. Uruçuí alcançou o segundo maior PIB per capita do estado com $\mathrm{R} \$ 59.528,58$, fato ocorrido devido principalmente a produção de soja e milho.

O município de Uruçuí patenteia relevante performance sobre o rendimento médio da produção granífera, sobretudo, a soja. Localizado no sudoeste do Estado do Piauí, às margens do rio Parnaíba, que divide os estados do Piauí e Maranhão, com uma posição geográfica privilegiada ao abrigo da seca, possui ainda vales extensos e férteis, uma rede de rios e ribeirões, o que a torna uma das mais ricas do Estado (SILVA et al., 2017).

Diante de cenários de incertezas climáticas, o setor agrícola que possui alta demanda de água, precisa procurar estratégias de manejo da irrigação, devido à escassez de recursos hídricos, visando assim, a disponibilidade de informação precisa para o produtor irrigante aumentar a eficiência de uso 
da água, além da fundamental importância para a sustentabilidade produtiva e ambiental (COELHO et. al., 2020).

A reduzida disponibilidade hídrica e a distribuição irregular das precipitações pluviais, que em muitas vezes coincidem com a fase crítica das culturas nas diferentes regiões do país, são as principais variáveis meteorológicas determinantes de oscilações no rendimento de grãos da cultura da soja. A soja tem sido usada como uma alternativa para rotação de culturas nas lavouras irrigadas, sendo, nestes casos, semeada principalmente após a época recomendada. Nessas condições, ela apresenta perdas de rendimentos por estar exposta a fatores que podem ser limitantes à produtividade da cultura (KUSS et al., 2008).

Para o bom desenvolvimento da cultura da soja em uma determinada região é necessário, entre outras coisas, condições climáticas como a precipitação, temperatura e fotoperíodo favoráveis (GIANLUPPI et al., 2009). A água constitui aproximadamente 90\% do peso da planta e atua praticamente em todos os processos fisiológicos e bioquímicos, sendo de grande importância principalmente em dois períodos de desenvolvimento da soja: a fase de germinação/emergência e floração/enchimento de grãos (EMBRAPA, 2011).

Segundo Ashraf et al. (2017), a utilização de estratégias de manejo da irrigação torna-se fundamental para o sucesso da agricultura irrigada, pois, a decisão sobre o momento apropriado (quando) e a quantidade adequada (quanto) de água a ser aplicada são baseadas em conceito prático do agricultor, conduzindo a falta ou excesso desse elemento para a cultura. O consumo crescente de água em razão do aumento populacional conduz a sua diminuição, exigindo procedimentos para a racionalização, principalmente no uso agrícola.

O conhecimento do desempenho das espécies vegetais diante da aplicação do manejo da irrigação com déficit regulado pode ser de grande valia quando se almeja uma ampliação na produtividade da água e pode explicar a capacidade de tolerância e/ou sensibilidade à deficiência hídrica das culturas quando imposta ao longo de seus diferentes estádios fenológicos, tendo em vista que os efeitos dos déficits hídricos variam com os estádios em que os mesmos se manifestam e cujas respostas podem até apontar efeitos nocivos do déficit sob o desenvolvimento e produção, embora possam resultar em um equilíbrio funcional entre a água empregada e o potencial produtivo alcançado (SILVA et al., 2012).

Neste contexto, o presente trabalho visa avaliar as respostas da cultura da soja à irrigação plena e a diferentes regimes de déficit hídrico durante seus estádios fenológicos, no intuito reunir informações que permitam diagnosticar a viabilidade técnica da aplicação da irrigação deficitária nesta cultura, nas condições edafoclimáticas do cerrado piauiense, visando a sustentabilidade dos recursos hídricos disponíveis.

\section{MATERIAL E MÉTODOS}

O trabalho foi conduzido em vasos a céu aberto, durante os meses de março a julho de 2020, na Universidade Estadual do Piauí (UESPI), no município de Uruçuí-PI, com coordenadas geográficas de $07^{\circ} 13^{\prime} 46^{\prime \prime} \mathrm{S}$, $44^{\circ} 33^{\prime} 22^{\prime \prime} \mathrm{W}$ e altitude média de $167 \mathrm{~m}$, numa área que compreende o bioma cerrado.

O clima da região, segundo a classificação de Köppen, é do tipo Aw, tropical, com temperatura média de $27,2{ }^{\circ} \mathrm{C}$ e precipitação média anual variando de 750 a $2000 \mathrm{~mm}$. A precipitação pluviométrica e melhor regularidade de distribuição das chuvas ocorre entre outubro e março e o período seco, com déficit hídrico, de abril a setembro. O veranico, estiagem durante a estação chuvosa, com dias de calor intenso e insolação que ocorre geralmente no mês de janeiro, é classificado como pequeno sendo o menos frequente dentre os cerrados nordestinos (MOREIRA NEVES et al., 2015).

Os materiais vegetais utilizados foram a cultivar NS8397 que possui como pontos fortes seu alto peso de grãos, excelente 
potencial produtivo e alta capacidade de engalhamento, com hábito de crescimento indeterminado, grau de maturação de $8.3 \mathrm{e}$ ciclo total variando de 110 a 133 dias. Já a cultivar J003, possui como principais características, boa capacidade de engalhamento, precocidade baixa, com ciclo variável de 95 a 110 dias, além de bom potencial produtivo. Ambas cultivares avaliadas são cultivadas na região do cerrado sul piauiense.

A área útil total ocupada com a cultura da soja foi de $8,0 \times 8,0 \mathrm{~m}=64,0 \mathrm{~m}^{2}$, onde foram instalados os 128 vasos plásticos, que possuíam volume de 5 litros, cada, sendo distribuídos no espaço de acordo com o delineamento estatístico adotado. Cada parcela, individualmente, ocupava uma área útil de 2,0 $\mathrm{m}^{2}$, sendo composta por quatro vasos, distribuídos em oito linhas de plantio. Já as subparcelas ocuparam, isoladamente, uma área útil de $1,0 \mathrm{~m}^{2}$, sendo composta por apenas dois vasos.

Os vasos utilizados para a condução do experimento eram de material plástico flexível, com capacidade volumétrica de 5 Litros, possuíam orifícios na extremidade inferior, que objetivavam promover a remoção dos eventuais excessos de água.

Como substrato para o cultivo das plantas, foi utilizado um solo de textura média, que de acordo com sua análise granulométrica possuía teores de $680 \mathrm{~g} \mathrm{~kg}^{-1}$ de Areia; $140 \mathrm{~g}$ $\mathrm{kg}^{-1}$ de Silte e $180 \mathrm{~g} \mathrm{~kg}^{-1}$ de Argila. Os atributos químicos do solo extraídos de uma amostra da camada de 0,0 a $0,20 \mathrm{~m}$ foram: $\mathrm{pH}$ $\left(\mathrm{CaCl}_{2}\right) \quad 7,3$; Teores de M.O (Matéria orgânica) $5,3 \mathrm{~g} \mathrm{~kg}^{-1} ; \mathrm{P}\left(15,7 \mathrm{mg} \mathrm{dm}^{-3}\right) ; \mathrm{K}(0,23$ cmol dm$\left.{ }^{-3}\right)$; Ca $\left(2,10 \mathrm{cmol} \mathrm{dm}^{-3}\right) ; \mathrm{Mg}(0,72$ $\left.\mathrm{cmol} \mathrm{dm}{ }^{-3}\right) ; \mathrm{Al}\left(0,00 \mathrm{cmol} \mathrm{dm}^{-3}\right) ; \mathrm{H}+\mathrm{A} \ell$ $\left(0,61 \mathrm{cmol} \mathrm{dm}^{-3}\right)$; SB $\left(3,05 \mathrm{cmol} \mathrm{dm}^{-3}\right)$; CTC $\left(3,67 \mathrm{cmol} \mathrm{dm}^{-3}\right) ; \mathrm{V}(83,3 \%)$ e $\mathrm{m}(0 \%) ; \mathrm{S}$ $\left(4,03 \mathrm{mg} \mathrm{dm}^{-3}\right) ; \mathrm{Fe}\left(327,1 \mathrm{mg} \mathrm{dm}^{-3}\right) ; \mathrm{Mn}(60,6$ $\left.\mathrm{mg} \mathrm{dm}{ }^{-3}\right) ; \mathrm{Cu}\left(1,6 \mathrm{mg} \mathrm{dm}^{-3}\right) ; \mathrm{Zn}\left(2,2 \mathrm{mg} \mathrm{dm}^{-}\right.$ $\left.{ }^{3}\right)$.

Para melhorar as propriedades físicas e químicas do solo, foram misturados uma proporção (1:1) de $50 \%$ de solo para $50 \%$ de composto orgânico (a base de esterco de bode, folhas e cinza), onde na sequência, procedeu- se com o preenchimento dos vasos. As adubações foram realizadas a cada 15 dias, utilizando-se como fonte de nutrientes o biofertilizante bovino, preparado através do processo de fermentação aeróbica, depois de um período de 30 dias. O plantio foi feito semeando-se em média de quatro a cinco sementes por cova. O desbaste foi realizado manualmente, rente ao solo, deixando-se duas plantas por cova, de forma a se obter o estande de plantas almejado pelo experimento.

$\mathrm{O}$ ciclo da cultura da soja foi dividido em três estádios fenológicos (I, II e III), assim distribuídos: estádio fenológico I, da emergência aos 48 dias após a emergência (DAE) (VE a V6); estádio fenológico II, dos 49 aos 89 DAE (R1 a R6) e estádio fenológico III, dos 90 aos 120 DAE (R7 a R9).

$\mathrm{O}$ experimento obedeceu a um delineamento estatístico de blocos ao acaso em esquema de parcelas subdivididas, com três repetições, onde nas parcelas estavam alocados os tratamentos da imposição ou não dos déficits hídricos (50 e 100\% da ETo) em diferentes estádios de desenvolvimento (sendo, T1 - Sem déficit hídrico durante os três estádios fenológicos (controle); T2 Déficit hídrico no estádio fenológico III; T3 Déficit hídrico no estádio fenológico II; T4 Déficit hídrico nos estádios fenológicos II e III; T5 - Déficit hídrico no estádio fenológico I; T6 - Déficit hídrico nos estádios fenológicos I e III; T7 - Déficit hídrico nos estádios fenológicos I e II e T8 - Com déficit hídrico durante os estádios fenológicos I, II e III) e nas subparcelas as cultivares.

O manejo da irrigação foi efetuado utilizando-se da evapotranspiração de referência ETo para a aplicação das lâminas de irrigação.

A lâmina de irrigação a ser aplicada foi calculada com o auxílio de uma planilha eletrônica onde estavam registrados os valores diários de evapotranspiração de referência (ETo), estimadas pelo método de PenmanMonteith utilizando dados climáticos obtidos do Instituto Nacional de Meteorologia (INMET), em estação agrometeorológica automática localizada no município de Uruçuí, Piauí. 


\section{PRODUTIVIDADE DA CULTURA DA SOJA IRRIGADA COM DÉFICIT HÍDRICO REGULADO NO CERRADO PIAUIENSE}

Para a aplicação da água de irrigação, em $\mathrm{mL}$, utilizou-se uma proveta de $1000 \mathrm{~mL}$, calculando-se o volume a ser aplicado de acordo com a área do vaso e a ETo:

Vol $=1000 \times$ Av $\times$ ETo
Em que: Vol = Volume de água a ser aplicado, em $\mathrm{mL} ; \quad \mathrm{ETo}=$ evapotranspiração de referência, em $\mathrm{mm} ; \mathrm{Av}=$ Área da superfície do vaso, $\mathrm{em} \mathrm{m}^{2}$.

As lâminas acumuladas, decorrentes da aplicação dos diferentes tratamentos de imposição do déficit hídrico regulado estão apresentadas na Tabela 1.

Tabela 1. Lâminas totais de água aplicadas nos diferentes tratamentos de imposição do déficit hídrico regulado.

\begin{tabular}{lc}
\multicolumn{1}{c}{ Tratamentos } & Lâminas aplicadas (mm) \\
\hline T1 - Sem déficit hídrico ao longo de todo o ciclo (controle) & 740,47 \\
T2 - Déficit hídrico no estádio fenológico III & 635,56 \\
T3 - Déficit hídrico no estádio fenológico II & 604,66 \\
T4 - Déficit hídrico nos estádios fenológicos II e III & 512,11 \\
T5 - Déficit hídrico no estádio fenológico I & 579,98 \\
T6 - Déficit hídrico nos estádios fenológicos I e III & 487,43 \\
T7 - Déficit hídrico nos estádios fenológicos I e II & 456,58 \\
T8 - Com déficit hídrico ao longo de todo o ciclo & 370,23 \\
\hline
\end{tabular}

Para a quantificação das componentes de produção da cultura da soja, foram determinados por ocasião da colheita: Altura média de inserção da primeira vagem (APV) -aferida a partir da superfície do solo até a inserção da primeira vagem; Número de vagens por planta (NVP) - contadas todas as vagens das plantas existentes na área útil da parcela; Número de ramificações $(\mathrm{NRm})$ - realizada através da contagem direta das ramificações emitidas pelas plantas existentes na área útil da parcela; Número de grãos por planta $\left(\mathrm{N}_{\mathrm{GR}}\right)$ - determinado através da contagem dos grãos produzidas por planta em cada parcela experimental e Potencial produtivo total (PPT) avaliada na colheita final, após a colheita e beneficiamento através de debulha manual das vagens e pesagem dos grãos colhidos na área útil de cada parcela, depois corrigindo os valores para expressão em kg por hectare.

Para a análise estatística foi utilizado o software SISVAR (FERREIRA, 2011). Para interpretação dos resultados, realizou-se análise da variância, aplicando-se o teste de "F" e quando significativo, aplicou-se o teste de Scott-Knott para comparação das médias dos tratamentos.

\section{RESULTADOS E DISCUSSÃO}

Na Tabela 2 estão expressos os resumos das análises de variâncias para os dados das variáveis de produção, sendo: APV - Altura de inserção da primeira vagem; NVP Número de vagens por planta; NRm - Número de ramificações; $\mathrm{N}_{\mathrm{GR}}$ - Número de grãos por planta e PPT - Potencial Produtivo Total de duas cultivares de soja submetidas a diferentes estratégias de irrigação deficitária ao longo do seu ciclo produtivo.

Pelos resultados observa-se que nenhuma variável de produção foi influenciada significativamente pela interação entre os fatores estudados (Irrigação deficitária $\mathrm{x}$ Cultivares).

No entanto, observando os fatores avaliados isoladamente, percebe-se que todas as variáveis de produção, exceto o número de 
ramificações, sofreram influência significativa (a 1 e $5 \%$ de significância), desta forma, expressou-se os resultados através da análise isolada mediante os fatores da irrigação deficitária e das cultivares.

Tabela 2. Análise de variância para os dados das variáveis de produção da cultura da soja submetida a diferentes estratégias de irrigação deficitária ao longo do seu ciclo produtivo

\begin{tabular}{ccccccc}
\hline \multirow{2}{*}{ FV } & \multirow{2}{*}{$\mathrm{GL}$} & \multicolumn{5}{c}{ Quadrados Médios } \\
\cline { 3 - 7 } & & $\mathrm{A}_{\mathrm{INS}}$ & $\mathrm{N}_{\mathrm{VG}}$ & $\mathrm{NRm}$ & $\mathrm{N}_{\mathrm{GR}}$ & PPT \\
\hline BLOCO & 2 & $170,68^{\text {ns }}$ & $7569,81^{\text {ns }}$ & $1945,1^{\text {ns }}$ & $37953,27^{\text {ns }}$ & $55837087,45^{\text {ns }}$ \\
I.DEFICIT (A) & 7 & $7,30^{* *}$ & $371,95^{* *}$ & $212,54^{\text {ns }}$ & $2399,90^{* *}$ & $3302994,30^{* *}$ \\
Erro (A) & 14 & 0,94 & 11,42 & 97,22 & 284,19 & 361704,66 \\
CULTIVAR (B) & 1 & $0,52^{*}$ & $44,08^{* *}$ & $105,25^{\text {ns }}$ & $270,75^{* *}$ & $424094,16^{* * *}$ \\
INT. A x B & 7 & $0,09^{\text {ns }}$ & $2,17^{\text {ns }}$ & $56,77^{\text {ns }}$ & $14,84^{\text {ns }}$ & $13132,69^{\text {ns }}$ \\
Erro (B) & 16 & 0,08 & 3,97 & 59,73 & 12,33 & 26888,44 \\
\hline Total & 47 & & & & & \\
\hline CV A (\%) & - & 9,45 & 15,35 & 53,48 & 14,43 & 15,69 \\
CV B (\%) & - & 2,80 & 4,01 & 41,92 & 3,01 & 4,28 \\
\hline
\end{tabular}

FV - Fonte de variação; GL - Graus liberdade; BL - Blocos; I. DEFICIT -Irrigação deficitária; CULTIVAR - Cultivares; CV Coeficientes de variações; AINS - Altura de inserção da primeira vagem; $\mathrm{NVG}_{\mathrm{VG}}$ - Número de vagens por planta; $\mathrm{NRm}$ - Peso de vagens por planta; NGR - Número de grãos por planta e PPT - Potencial Produtivo Total; ** significativo a $1 \%$ de probabilidade; * significativo a $5 \%$ de probabilidade e; ns não significativo pelo teste $\mathrm{F}$, respectivamente.

Na Figura 1A, observa-se as médias da altura de inserção da primeira vagem em função das diferentes estratégias de irrigação deficitária utilizadas. A maior altura de inserção da primeira vagem $(12,33 \mathrm{~cm})$ foi obtida no tratamento $\mathrm{T} 1$, referente a aplicação da lâmina de $100 \%$ da ETo durante todo o ciclo da cultura, no entanto, tal resultado não diferiu estatisticamente $(p \geq 0,05)$ do resultado alcançado no tratamento T2, que corresponde a aplicação da lâmina deficitária (50\% da ETo) apenas no estádio fenológicos III (dos 90 aos 120 dias após a emergência).

Quanto aos valores médios obtidos pelas cultivares avaliadas (Figura 1B), notou-se que a maior AINS foi obtida para a cultivar NS 8397 com $10,41 \mathrm{~cm}$.
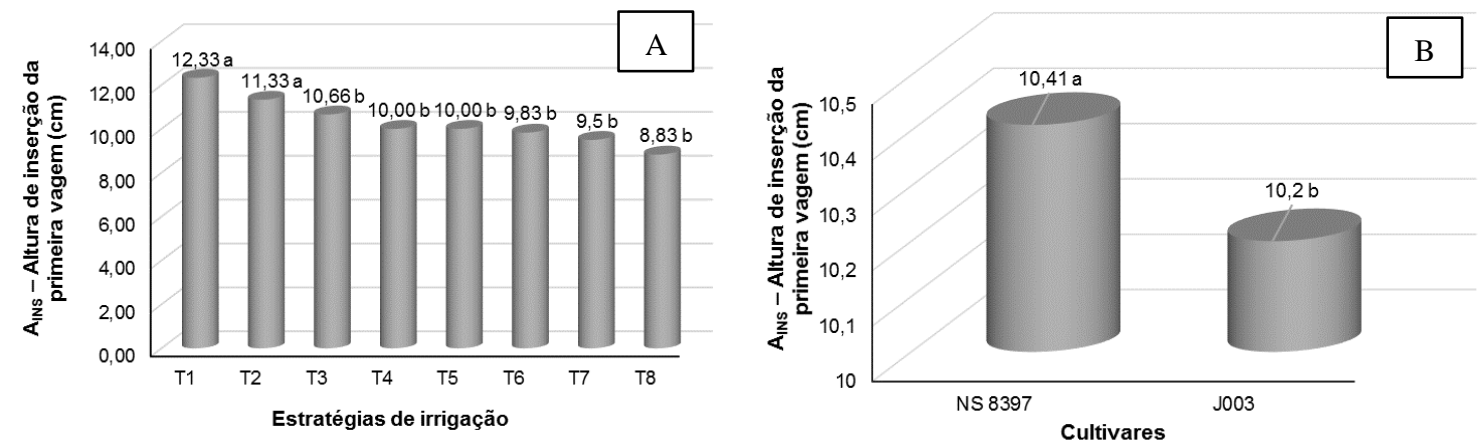

Figura 1. Altura de inserção da primeira vagem (AINS) de duas cultivares de soja submetidas a diferentes estratégias de irrigação deficitária ao longo do seu ciclo produtivo. Médias seguidas pela mesma letra não diferem em si pelo teste de Scott-Knott a 5\% de probabilidade.

O fato do resultado alcançado no tratamento 2 não ter se diferenciado estatisticamente do tratamento T1 pode ser explicado em virtude do déficit hídrico ser imposto apenas na fase final do ciclo da $\begin{array}{llll}\text { cultura } & \text { (dos } & 90 & \text { aos }\end{array}$
120 dias após a emergência), período este, onde a cultura já estava plenamente estabelecida, devido a lâmina de água aplicada ser plena (100\% da ETo) durante os estádios fenológicos I e II, fases estas que coincidem com o estabelecimento vegetativo e de 
floração e/ou formação das vagens da cultura da soja.

Contrariando os resultados obtidos na presente pesquisa, Gava et al. (2016), estudando a irrigação com déficit em diferentes fases da cultura da soja, constataram que não houve diferença entre os tratamentos para esta variável. Segundo os autores, a resposta desta variável pode estar mais relacionada com as características genéticas da cultura, do que com os fatores externos impostos.

Resultados superiores aos obtidos no presente trabalho foram constatados por Ormond et al. (2015), que avaliando as características agronômicas relacionadas com a produção de soja em sistemas de semeadura convencional e cruzada, encontraram valores médios da altura de inserção da $1^{\circ}$ vagem de 13,57 e $13,00 \mathrm{~cm}$, respectivamente.

Durante a execução da colheita mecanizada, a altura de inserção da primeira vagem possui grande influência nesta operação, pois, quando as vagens ficam muito próximas ao solo, as perdas por ocasião da colheita podem ser expressivas. Segundo Carvalho et al. (2010), a barra de corte das maiorias das colheitadeiras situa-se aproximadamente a $10 \mathrm{~cm}$ da superfície do solo, desta forma, os resultados alcançados nos tratamentos T6, T7 e T8, ficaram fora desse padrão requerido, o que acarretaria, possivelmente, diminuição da produtividade.

$\mathrm{Na}$ Figura 2A, observa-se as médias do número de vagens em função das diferentes estratégias de irrigação deficitária utilizadas. O maior número de vagens por planta produzidas (62,66 unidades) foi obtido no tratamento T1 (100\% da ETo durante todo o ciclo da cultura), no entanto, tal resultado não diferiu estatisticamente $(p>0,05)$ dos alcançados nos tratamentos T2 e T3, com 56,50 e 54,33 unidades, respectivamente. Tal resultado pode ser atribuído a boa disponibilidade hídrica ofertada a cultura durante o período vegetativo, o que nos permite inferir que durante os períodos de déficit hídrico impostos (nos estádios fenológicos II e III), a planta conseguiu manter as taxas de elongação celular e atividade fotossintética necessárias para o crescimento e manutenção das estruturas verdes (MUNDSTOCK \& THOMAS, 2005).

Na comparação entre os tratamentos T1 e T8, houve uma diferença percentual de $38,8 \%$ quanto ao número de vagens emitidas, demonstrando assim a importância que a adequada disponibilidade hídrica ocasiona sobre a emissão de novas vagens. Quanto ao desempenho das cultivares avaliadas (Figura 2B), notou-se que a cultivar NS 8397 foi a que melhor se destacou quanto a emissão de $\mathrm{N}_{\mathrm{VG}}$.
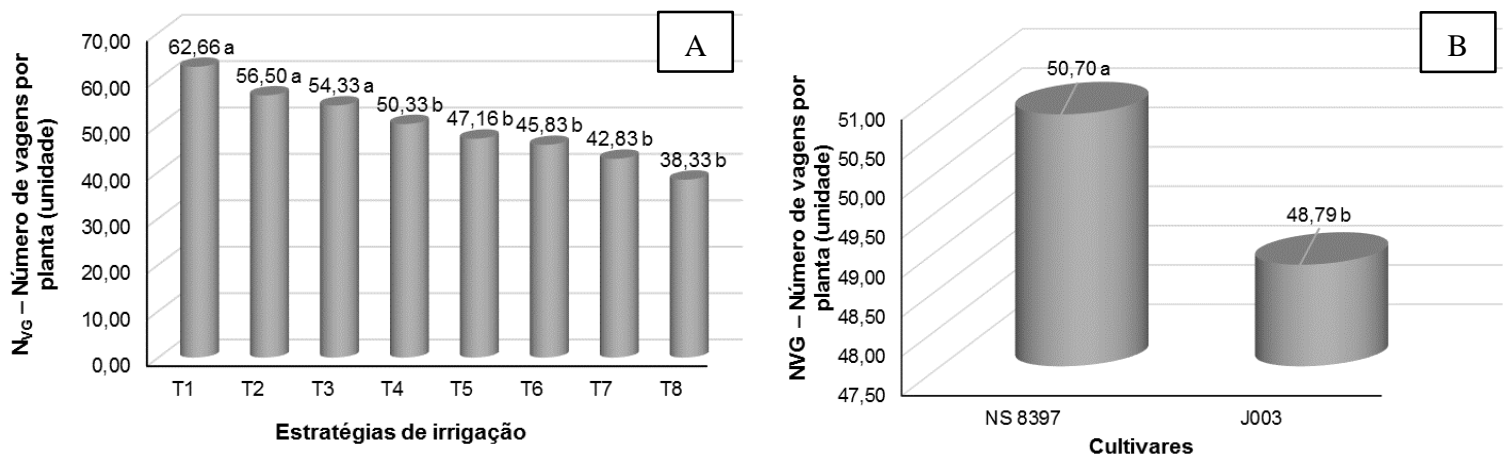

Figura 2. Número de vagens por planta (NVG) de duas cultivares de soja submetidas a diferentes estratégias de irrigação deficitária ao longo do seu ciclo produtivo. Médias seguidas pela mesma letra não diferem em si pelo teste de Scott-Knott a $5 \%$ de probabilidade.

Resultados similares foram apresentados por Barbosa et al. (2013), onde, avaliando o desempenho agronômico e componentes da produção de cultivares de soja em duas épocas de semeadura no arenito caiuá, constataram um número médio de vagens na primeira época de semeadura de 61,2 unidades. Entre as cultivares avaliadas, a que apresentou melhor 
desempenho quanto a emissão de vagens por planta foi a BRS 262, com 78,9 unidades. Os autores destacam ainda que, a superioridade apresentada pela cultivar (BRS 262), se deu, provavelmente, em virtude de ser uma cultivar pertencente ao grupo de maturação médio, sendo o número de dias compreendido entre os estádios R1 e R4 maior, diminuindo substancialmente o impacto de estresses hídrico e térmico pontuais, ocorridos durante a condução do experimento.

Segundo Farias, Nepomuceno e Neumaier (2007), temperaturas elevadas (próximas aos $40{ }^{\circ} \mathrm{C}$ ), principalmente quando associadas à ocorrência de déficit hídrico, tem efeito adverso na taxa de crescimento e provocam distúrbios na floração, diminuindo a capacidade de retenção de vagens (EMBRAPA, 2011). Tais informações vão de encontro, portanto, aos resultados obtidos no tratamento T8, onde a imposição da lâmina deficitária (50\% da ETo) ao longo de todo o ciclo de desenvolvimento da cultura propiciou o menor número de vagens emitidas por plantas, com apenas 38,33 unidades.

As médias dos números de grãos por planta $\left(\mathrm{N}_{\mathrm{GR}}\right)$ em função das diferentes estratégias de irrigação deficitária utilizadas podem ser visualizadas na Figura 3A. O maior número de grãos por planta produzido $(146,83$ g planta $\left.^{-1}\right)$ foi obtido no tratamento T1 $(100 \%$ da ETo durante todo o ciclo da cultura), no entanto, tal resultado não difere estatisticamente em si, aos resultados alcançados nos tratamentos T2, T3 e T4. Entre as cultivares avaliadas, a NS 8397 foi a que produziu maior número médio de grãos com 119,20 unidades (Figura 3B).
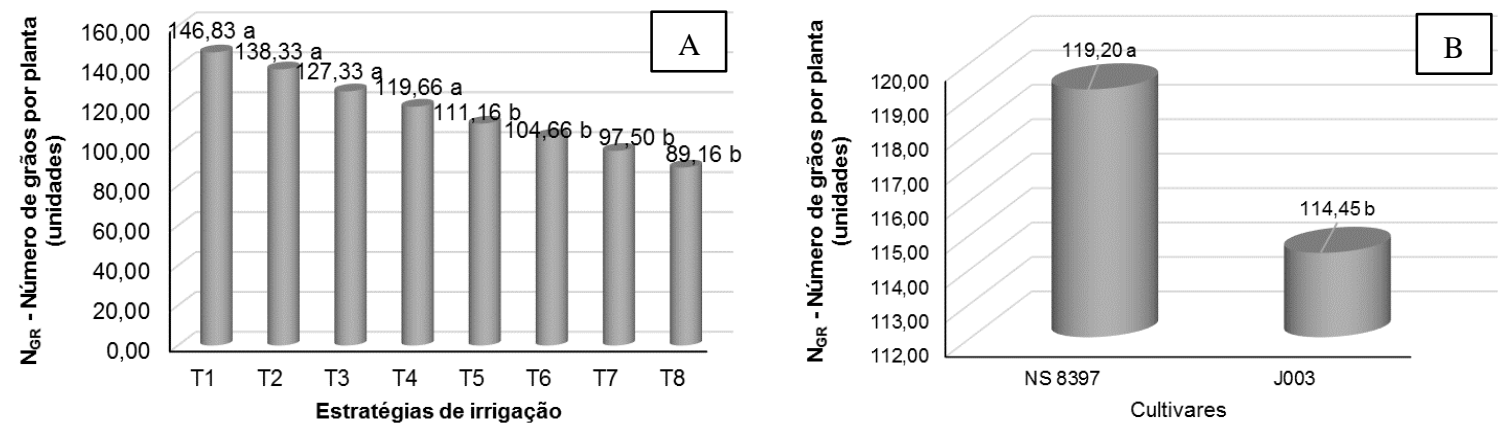

Figura 3. Número de grãos por planta (NGR) de duas cultivares de soja submetidas a diferentes estratégias de irrigação deficitária ao longo do seu ciclo produtivo. Médias seguidas pela mesma letra não diferem em si pelo teste de Scott-Knott a $5 \%$ de probabilidade.

Santos et al. (2014), analisando o efeito de sistemas de rotação de culturas no número de grãos por planta de soja de 1996/1997 a 2010/2011, em Passo Fundo - RS, constataram um número médio 64 unidades, resultado este, bem inferior ao constatado neste trabalho. Os autores atribuíram o baixo número de grãos obtidos ao excesso de precipitação pluvial, acima do normal ocorrido durante a execução do trabalho.

Resultados semelhantes aos encontrados no presente trabalho, foram alcançados por Fioreze et al. (2011), onde, avaliando o comportamento e as características envolvidas nas respostas de três genótipos de soja, submetidos à indução de déficit hídrico de alta intensidade em casa de vegetação, constataram que o genótipo CD 201 obteve o maior número de grãos por planta com um valor máximo de 130 unidades.

Entre os tratamentos T1 $(100 \%$ da ETo durante todo o ciclo da cultura) e T8 (50\% da ETo durante todo o ciclo da cultura), houve uma diferença percentual da ordem de 39,3\%. Tal resultado aponta para o efeito nocivo que o déficit hídrico ocasiona a esta componente de produção da cultura da soja. Pois, segundo Mundstock \& Thomas (2005), a pouca disponibilidade de água ao longo do ciclo da cultura da soja, principalmente, durante os estádios de florescimento e início de formação das vagens, caracteriza-se uma situação dramática para a lavoura, sendo esse o período mais sensível da planta ao déficit hídrico, pois 
os efeitos se darão sobre o abortamento de flores, óvulos e vagens, posteriormente, sobre o tamanho dos grãos.

O potencial produtivo total $(\mathrm{PPT})$ da cultura da soja em função das diferentes estratégias de irrigação deficitária está expresso na Figura 4A. O maior potencial produtivo alcançado (4871,14 $\mathrm{kg} \mathrm{ha}^{-1}$ ) foi obtido no tratamento T1, referente a aplicação da lâmina de $100 \%$ da ETo durante todo o ciclo da cultura, no entanto, tal resultado não difere estatisticamente em si $(\mathrm{p}>0,05)$ pelo teste de Scott-Knott, dos resultados obtidos nos tratamentos $\mathrm{T} 2$, T3 e T4. Já na Figura 4B, observou-se, entre as cultivares avaliadas, que a NS 8397 foi a que obteve maior PPT com $3926,80 \mathrm{~kg}$ $\mathrm{ha}^{-1}$.
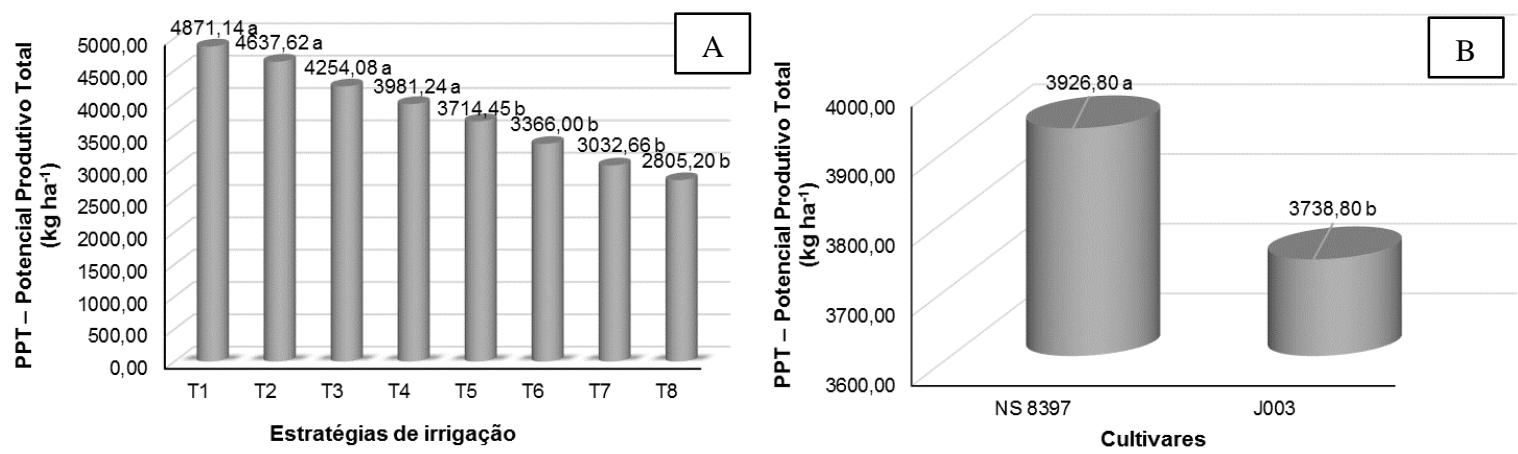

Figura 4. Potencial Produtivo Total (PPT) de duas cultivares de soja submetida a diferentes estratégias de irrigação deficitária ao longo do seu ciclo produtivo. Médias seguidas pela mesma letra não diferem em si pelo teste de Scott-Knott a $5 \%$ de probabilidade.

Corroborando com os resultados obtidos no presente trabalho, Barzotto et al. (2016) avaliando a cultivar de soja BMX Ativa em diferentes níveis de água $(350,425,525,575$ e $600 \mathrm{~mm}$ ) observaram que o valor da produtividade máxima de grãos de $4827 \mathrm{~kg} \mathrm{ha}^{-}$ 1, obtida com a lâmina de irrigação de 575 $\mathrm{mm}$.

Gomes et al. (2014), avaliando as componentes de produção de duas cultivares de soja (CD 219 e AL 55) sob seis estratégias de irrigação baseadas na evapotranspiração de referência (ETo) estimada por um tanque classe A, constataram uma produção média de $3427,9 \mathrm{~kg} \mathrm{ha}^{-1}$, obtida com a aplicação de uma lâmina de irrigação referente a $100 \%$ da ETo.

$\mathrm{Na}$ comparação entre os tratamentos referentes a aplicações das lâminas de 100 e $50 \%$ da ETo durante todo o ciclo da cultura, denotou-se uma diferença percentual da ordem de $42,4 \%$.

Resultado este que, demonstra de maneira expressiva, os efeitos prejudiciais que o déficit hídrico ocasiona sobre o rendimento de grãos da cultura da soja.

A disponibilidade de água é importante, particularmente, em dois períodos de desenvolvimento da soja: germinação emergência (4 a 5 dias) e floração-enchimento de grãos. Desta forma, déficits hídricos expressivos, durante a floração e o enchimento de grãos, provocam alterações fisiológicas na planta (fechamento estomático e oenrolamento de folhas) causando a queda prematura das folhas e de flores e abortamento de vagens, resultando, por fim, em redução do rendimento de grãos e comprometendo a produtividade da cultura (EMBRAPA 2013).

Segundo Fioreze et al. (2011), um correto entendimento de como o déficit hídrico afeta o desenvolvimento das culturas seria de grande ajuda para a criação de mais cultivares tolerantes à seca, por meio da identificação de características especificas, que determinam a performance de culturas em condições de déficit hídrico e que são passíveis de alterações, seja por transformação genética, seja por melhoramento genético convencional. 
Barbosa et al.

\section{CONCLUSÕES}

As componentes produtivas da cultura da soja (altura de inserção da primeira vagem, número de vagens por planta, número de grãos por planta e o potencial produtivo total) obtiveram melhores respostas, principalmente, quando irrigadas com uma lâmina de irrigação referente a $100 \%$ da ETo durante o estádio fenológicos I.

O déficit hídrico controlado $(50 \%$ da ETo) aplicado, principalmente, nas fases de floração e enchimento de grãos na cultura soja, ocasionou diminuições drásticas nas componentes produtivas (número de vagens por planta, número de grãos por planta e potencial produtivo total).

A cultivar NS 8397 demonstrou ser mais adaptada e tolerante as condições de déficit hídrico impostas, sendo, portanto, mais recomendada para o cultivo na região do cerrado sul piauiense.

\section{AGRADECIMENTOS}

Os autores agradecem a Universidade Estadual do Piauí (UESPI) pela concessão da bolsa de iniciação científica para a execução desta pesquisa.

\section{REFERÊNCIAS}

ASHRAF, M.; SHAHZAD, S. M.; AKHTAR, N.; IMTIAZ, M.; ALI, A. Salinization/sodification of soil and physiological dynamics of sunflower irrigated with saline sodic water amending by potassium and farm yard manure. Journal of Water Reuse and Desalination, v.7, p.476 487, 2017.

BANCO DO NORDESTE. Produção de Grãos do Nordeste em 2020. DEE - Diário Econômico ETENE (Escritório Técnico de Estudos Econômicos do Nordeste), Ano III, $\mathrm{n}^{\mathrm{o}}$ 3, ISSN 2594-7338. Disponível em: https://bnb.gov.br/documents/1342439/601083 7/03_17_01_2020.pdf/caf728eb-52f3-3f24- b1cf-c95be2684670. Acesso em: 20 de ago de 2020.

BARBOSA, M. C.; BRACCINI, A. de L. e; SCAPIM, C. A.; ALBRECHT, L. P.; PICCININ, G. G.; ZUCARELI, C. Desempenho agronômico e componentes da produção de cultivares de soja em duas épocas de semeadura no arenito caiuá. Semina: Ciências Agrárias, v. 34, n. 3, p. 945-960, 2013.

BARZOTTO, F.; ROBAINA, A. D.; PEITER, M. X.; TORRES, R. R.; KIRCHNER, J. H.; ROSSO, R. B.; GIRARDI, L. B.; MEZZOMO, W. Efeito da irrigação e da adubação nitrogenada nos parâmetros de desenvolvimento e nos componentes de produção da cultura da soja. Revista Espacios. v. 37, n. 21, 2016.

CARVALHO, E. R.; REZENDE, P. M.; OGOSHI, F. G. A.; BOTREL, E. P.; ALCANTARA, H. P.; SANTOS, J. P. Desempenho de cultivares de soja [Glycine $\max ($ L.) Merrill] em cultivo de verão no sul de Minas Gerais. Ciência e Agrotecnologia, v. 34, p.892-899. 2010.

CEPRO - Fundação Centro de Pesquisas Econômicas e Sociais do Piauí. PIB dos Municípios 2017. SUPERINTENDENTE DE ESTUDOS ECONÔMICOS E SOCIAIS (CEPRO), Teresina, 2019. Disponível em: http://www.cepro.pi.gov.br/pib.php. Acesso em: 19 de ago. 2020.

COELHO, E. F.; SANTOS, M. R. dos; CRUZ, R. O. da R.; LIMA, L. W. F.; BARROS, D. L. Irrigação com déficit regulado em diferentes fases de cultivo de bananeira 'BRS princesa'. Revista Brasileira de Agricultura Irrigada, v.14, no. 2, p. $3931-3940,2020$.

EMBRAPA - Empresa Brasileira de Pesquisa Agropecuária. Tecnologias de produção de soja - Região central do Brasil - 2012/2013. Londrina: Embrapa Soja, 2011. 262 p. (Sistemas de Produção / Embrapa Soja, 15). 
EMBRAPA - Empresa Brasileira de Pesquisa Agropecuária. Tecnologia de produção de soja: região central do Brasil. Brasília, 2013. 266 p. (Sistema de Produção, 16).

FARIAS, J. R. B.; NEPOMUCENO, A. L.; NEUMAIER, N. Ecofisiologia da soja. Londrina: Embrapa Soja, 2007. 10 p. (Embrapa soja, circular técnica, 48).

FERREIRA, D. F. Sisvar: a computer statistical analysis system. Ciência e Agrotecnologia, Lavras, v. 35, n.6, p. 10391042, 2011.

FIOREZE, S. L.; PIVETTA, L. G.; FANO, A.; MACHADO, F. R.; GUIMARÃES, V. F. Comportamento de genótipos de soja submetidos a déficit hídrico intenso em casa de vegetação. Revista Ceres, v. 58, n.3, p. 342-349, 2011.

GAVA, R.; FRIZZONE, J. A.; SNYDER, R. L.; ALMEIDA, B. M. de; FREITAS, P. S. L. de; REZENDE, R. Estratégias de manejo de déficit hídrico na irrigação da cultura da soja. Brazilian Journal of Biosystems Engineering, v. 10, n.3, p. 305-315, 2016.

GIANLUPPI, V. et al. Cultivo de soja no cerrado de Roraima. Sistema de Produção, Boa Vista: Embrapa Roraima, 2009. Disponível em: http://sistemasdeproducao.cnptia.embrapa.br/F ontesHTML/Soja/CultivodeSojanoCerradode Roraima/clima.htm. Acesso em: 18 ago. 2020.

GOMES, A. C. S.; ROBAINA, A. D.; PEITER, M. X.; SOARES, F. C.; PARIZI, A. R. C. Modelo para estimativa da produtividade para a cultura da soja. Ciência Rural, v. 44, n. 1, p. 43-49, 2014.

IBGE - INSTITUTO BRASILEIRO DE GEOGRAFIA E ESTATÍSTICA. Censo Agropecuário 2017: Resultados definitivos. Brasília: IBGE, 2019.
KUSS, R. C. R.; KÖNIG, O.; Dutra, L. M. C.; BELLÉ, R. A.; ROGGIA, S.; STURMER, G. R. Populações de plantas e estratégias de manejo de irrigação na cultura da soja. Ciência Rural, Santa Maria, Ciência Rural, v.38, n.4, 2008.

MOREIRA NEVES, S.; BARBOSA, A. M. F.; SOUZA, R. M. E. Análise geoambiental do município de Uruçuí-PI. Revista de Geografia, v. 32, n. 1, p.151 166, 2015.

MUNDSTOCK, C. M.; THOMAS, A. L. SOJA: Fatores que afetam o crescimento e o rendimento de grãos. Porto Alegre: Departamento de Plantas de Lavoura da Universidade Federal do Rio Grande do Sul: Evangraf, p. 31, 2005.

ORMOND, A. T. S.; VOLTARELLI, M. A.; PAIXÃO, C. S. S.; GÍRIO, L. A. da S.; ZERBATO, C.; SILVA R. P. da. Características agronômicas da soja em semeadura convencional e cruzada. Revista Agro@mbiente On-line, v. 9, n. 4, p. 414422, 2015.

SANTOS, H. P. dos.; FONTANELI, R. S.; PIRES, J.; LAMPERT, E. A.; VARGAS, A. M.; VERDI, A. C. Rendimento de grãos e características agronômicas de soja em função de sistemas de rotação de culturas. Bragantia, v. 73, n. 3, p.263-273, 2014.

SILVA, A. J. da.; MONTEIRO, M. do S. L.; BARBOSA, E. L. Territorialização da agricultura empresarial em Uruçuí/PI: de "espaço vazio" aos imperativos do agronegócio. Caderno de Geografia, v.27, Número Especial 1, p.138-158, 2017.

SILVA, A. R. A.; BEZERRA, F. M. L.; FREITAS, C. A. S.; PEREIRA FILHO, J. V.; ANDRADE, R. R.; FEITOSA, D. R. C. Morfologia e fitomassa do girassol cultivado com déficits hidricos em diferentes estádios de desenvolvimento. Revista Brasileira de Engenharia Agrícola e Ambiental, v.16, n.9, p.959-968, 2012. 